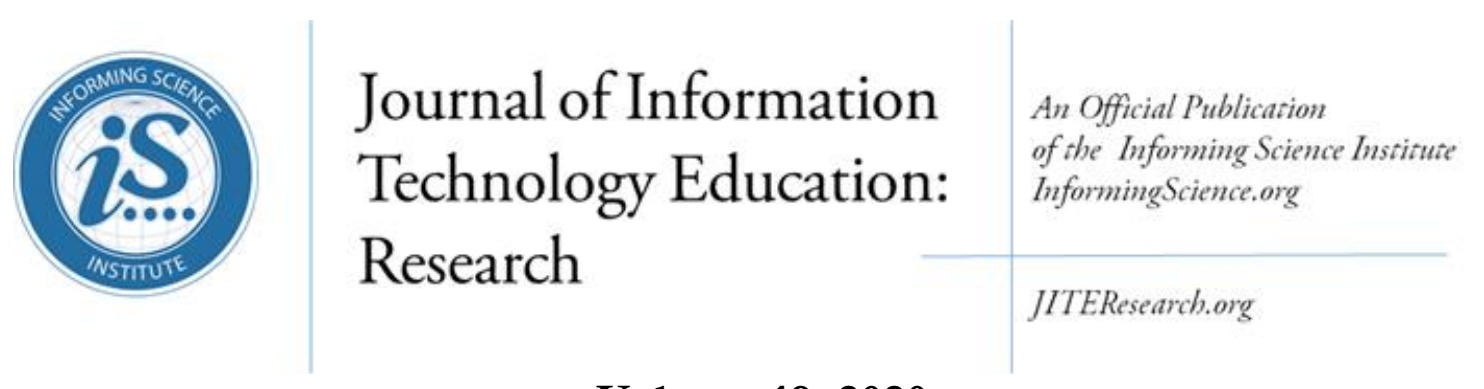

Volume 19, 2020

\title{
GAMIFICATION AS AN ENGAGEMENT TOOL IN E-LEARNING WEBSITES
}

\author{
Sofia Rebelo \\ Novabase, Lisbon, Portugal \\ Pedro Isaías* \\ Information Systems \& Technology \\ Management School, The University of \\ New South Wales (UNSW), Sydney, \\ NSW, Australia
}

sofia.crebelo@gmail.com

p.teixeira isaias@unsw.edu.au

* Corresponding author

\section{AbSTRACT}

Aim/Purpose

As e-Learning becomes increasingly pervasive, students' engagement in online settings emerges as a central challenge, as it is often more demanding to ensure in this context. The core importance of engagement for e-Learning, places a focus on various instruments and strategies that can be deployed to foster its enhancement.

Background

Gamification is often depicted as a significant instrument to drive engagement, behavior change, and loyalty, which can be of great significance to online learning. This paper aims to examine the relationship between the application of gamification tools and the level of engagement in e-Learning websites.

Methodology

This research used two methods: the analysis of e-Learning websites and an online survey with a convenience and purposive sample of e-Learning and/or gamification experts.

Contribution

This paper adds to the existing body of research by placing and emphasis on and examining the positive role of gamification as an engagement instrument with valuable potential for e-Learning.

Findings

The results showed that the majority of the selected e-Learning websites use gamification and engagement elements and that the tools that are more commonly used were deemed as the most effective, by the experts. It became equally evident that the deployment of a larger number of gamification and engagement elements have positive repercussions in the enhancement of engagement, which can have constructive ramifications for the effectiveness of eLearning.

Accepting Editor Peter Blakey | Received: August 4, 2020 | Revised: October 12, 2020 | Accepted: October 23, 2020.

Cite as: Rebelo, S., \& Isaías, P. (2020). Gamification as an engagement tool in e-learning websites. Journal of Information Technology Education: Research, 19, 833-854. https://doi.org/10.28945/4653

(CC BY-NC 4.0) This article is licensed to you under a Creative Commons Attribution-NonCommercial 4.0 International License. When you copy and redistribute this paper in full or in part, you need to provide proper attribution to it to ensure that others can later locate this work (and to ensure that others do not accuse you of plagiarism). You may (and we encourage you to) adapt, remix, transform, and build upon the material for any non-commercial purposes. This license does not permit you to use this material for commercial purposes 
Recommendations From a practitioner's viewpoint the findings can assist both learning designers for Practitioners and teachers in the creation of gamification strategies to enhance students' engagement. As a central challenge of e-Learning courses, engagement requires a multifaceted approach to be addressed effectively and knowing the strategies that have positive outcomes is a step forward in ensuring that the students can enroll in online courses and not be compromised with respect to their engagement. Finally, the lack of engagement can have serious repercussions not only on the learning experience of the students, but also on their actual academic performance. Hence, it is important to guide educators towards good design practices that can maximize engagement in these settings.

Recommendations From a research perspective, these findings add to a growing body of studies for Researchers that focus on the benefits of gamification by highlighting its positive repercussions on engagement and identifying which elements are more effective. In addition, the use of different sources of data provided a wider illustration of what is currently the use of gamification elements by functioning e-Learning websites and how those who apply them in practice in their courses perceive these elements.

Keywords gamification, engagement, e-learning

\section{INTRODUCTION}

E-Learning represents limitless opportunities for students, nonetheless, significant retention problems still remain in online education (Bawa, 2016). Despite having attracted millions of students eLearning courses still report substantial dropout rates (Hassan et al., 2019). Massive open online courses (MOOCs), for example, have not yet been able to improve their low completion rate, regardless of their popularity (Reich \& Ruipérez-Valiente, 2019). There are several factors influencing learners to continue an online course, such as motivation. Since e-Learning relies significantly on self-direction, the lack of motivation can be decisive for learners to dropout (Bawa, 2016) and reduce engagement. Similarly, some researchers have associated high levels of students' engagement to be connected to student retention. Prediction models to identify potential dropout students, that resort to engagement metrics, have a higher prediction accuracy (Aguiar et al., 2014).

Reducing the dropout rates in e-Learning is a complex endeavor that requires multiple approaches to address the various factors causing it. With concern to engagement and the role it plays in course abandonment, it is key to understand the learners' engagement in the course activities. The more the learners participate, the more engaging their experience becomes, and they become, consequently more likely to have a better academic performance and to complete the course (Hussain et al., 2018).

The manner in which students interact with the activities that are being developed in online courses can be used as a metric for their engagement in the learning experience. Previous studies have found a connection between engagement and performance in online learning courses (Georgakopoulos et al., 2018). Engaged learners can benefit from a variety of improvements in their learning experience, such as the enhancement of their motivation. The multiple advantages that engagement imports into the learning process has placed it at the center of increasing interest in online settings (Lee et al., 2019). Various strategies can be deployed in online learning settings to increase student engagement. Gamification represents one of the resources that teachers can apply to enhance engagement, in the sense that it has the potential to elicit motivation and engagement in the user as well as to conduce to behavioral change (Seaborn \& Fels, 2015). With a robust and well-structured design model, gamification can, equally, be an effective resolution to address challenges pertaining to motivation (Sailer et al., 2017). Hassan et al. (2019) proposed a framework that addressed the learning style of the students 
and offered a personalized gamification experience. The application of that experiment resulted in $25 \%$ increase in motivation and a $26 \%$ decrease in dropouts.

Given the central importance of enhancing student engagement in the context of e-Learning, this study aims to examine the relationship between the application of gamification tools and the level of engagement in e-Learning websites. This research was motivated by the need to explore viable strategies to enhance engagement in e-Learning settings, more specifically gamification, which has been positively highlighted in the education sector for its power to engage the user. To attain this goal, it is necessary to address two core research questions: (1) Are e-Learning websites using gamification and engagement elements? and (2) What are the most effective gamification and engagement elements? This paper begins by reviewing pertinent literature on engagement, gamification, and e-Learning to provide a sound theoretical background and explore the relationship between the three concepts. This section is then followed by a description of the methods and a presentation and discussion of the results. The final section highlights the most pertinent results and conclusions and suggests future research directions. The findings of this study expect to assist both researchers and practitioners to gain different insights and to understand different perspectives about the part that gamification can play in generating engagement in online learning. It equally intends to provide a foundation for a more effective use of specific game mechanisms for a more directed and engaging design.

\section{ENGAGEMENT}

There are many definitions of the term engagement, depending on the background in which they are applied, including in educational settings. In the context of learning it is possible to distinguish several variances of engagement, namely student engagement and learner engagement. The first is exclusive of academic settings, while the latter is more comprehensive and includes learning outside the formality of the academic milieu (Henrie et al., 2015). For the purpose of this study, it is relevant to define user engagement within the context of website use. Hence, the definition of Seedorf et al. (2014, p. 5) is pertinent: "User engagement is a multi-stage concept that describes how users become interested to interact with a system (e.g., a website) and spend time or pay attention to a product, prospect, or brand."

Engagement is central to education, but its measurement is challenging. It is paramount to define parameters to measure engagement in online learning, to understand when students are actually engaging with the platform and the materials. In the area of engagement measurement, Zichermann and Cunningham (2011) have argued that the degree of user engagement for a given webpage is not measured by just using one metric. The use of page views or an analysis of unique viewers' numbers are insufficient to determine who is engaged. Hence, the authors suggest that engagement should be perceived as being composed of the following interconnected metrics: recency, the extent to which the interactions are recent; frequency, how often the interactions on the website occur; duration, how long do the interactions last; virality, the extent to which it can become viral/be swiftly disseminated among users; and ratings, which refers to the user evaluation that is attributed. The inherent interest in this subject rises precisely from the importance of understanding the impact ratio that each of these factors has on engagement, which depends on the type of business in which it is integrated (Zichermann \& Cunningham, 2011). Due to their pertinence for this study, more quantitative indicators used by Alexa (2017) are also considered: daily time on site, daily page views per visitor, bounce rate, percentage of traffic from search engines, total sites linking in. According to Garett et al. (2016), website design has become a vital factor in determining user engagement. The framework that they proposed was used and adapted as a theoretical foundation for the main website design elements for user engagement: navigation, graphical representation, organization, content utility, purpose, simplicity, and readability (Table 1). 
Table 1 - Key website design elements for user engagement

(adapted from Garett et al., 2016)

\begin{tabular}{|c|c|c|}
\hline Design Elements & Definition & Examples of Indicators \\
\hline Navigation & Effortlessness of navigation & $\begin{array}{ll}\text { - } & \text { Noticeable menu } \\
\text { - } & \text { Search features }\end{array}$ \\
\hline $\begin{array}{l}\text { Graphical Repre- } \\
\text { sentation }\end{array}$ & $\begin{array}{l}\text { Usage of icons, multimedia } \\
\text { and } \\
\text { contrasting colors }\end{array}$ & $\begin{array}{l}\text { - } \quad \begin{array}{l}\text { Adequate image resolution and } \\
\text { size }\end{array} \\
\text { - } \quad \text { No visual overload }\end{array}$ \\
\hline Organization & $\begin{array}{l}\text { Existence of a logical organiza- } \\
\text { tion }\end{array}$ & $\begin{array}{ll}\text { - } & \text { Inclusion of keywords } \\
\text { - } & \text { Clear structure }\end{array}$ \\
\hline Content Utility & $\begin{array}{l}\text { Information's usefulness and } \\
\text { interest }\end{array}$ & $\begin{array}{l}\text { - Quality of content } \\
\text { - Content's pertinence to the na- } \\
\text { ture of the website }\end{array}$ \\
\hline Purpose & $\begin{array}{l}\text { Clear statement of the web- } \\
\text { site's purpose }\end{array}$ & $\begin{array}{ll}\text { - } & \text { Distinctive identity } \\
\text { - } & \text { Inclusion of contact infor- } \\
\text { mation }\end{array}$ \\
\hline Simplicity & Simple website design & $\begin{array}{ll}\text { - } & \text { Organized layout } \\
\text { - } & \text { Intuitive functions }\end{array}$ \\
\hline Readability & $\begin{array}{l}\text { Readable and understandable } \\
\text { website }\end{array}$ & $\begin{array}{ll}\text { - } & \text { Simple to read } \\
\text { - } & \text { Accurate spelling and grammar }\end{array}$ \\
\hline
\end{tabular}

These aspects of user interface (UI) are important to positively influence and forecast user engagement. Their impact is greater as more elements are applied. The authors also underlined that, although no publication mentioned cross-platform compatibility (compatibility with several devices and compatibility with several browsers) and social media integration, they should be taken into account due to their growing importance (Garett et al., 2016). These indicators for engagement measurement proposed by Zichermann and Cunningham (2011), Alexa (2017), and Garett et al. (2016) constitute the theoretical basis of the empirical research in terms of the identification and effectiveness of engagement elements in e-Learning.

\section{GAMIFICATION}

Gamification is framed in the research areas of Human-Computer Interaction (HCI) and games (Deterding, Dixon, et al., 2011). It can be seen as a useful tool to obtain engagement, motivation, behavior activation, and loyalty, positively enhancing the performance and productivity of employees, users or consumers (Deterding, Dixon, et al., 2011; Kankanhalli et al., 2012; Zichermann \& Cunningham, 2011). There are various definitions for the concept of gamification. Zichermann and Cunningham (2011, p. xiv) defined gamification as "the process of game-thinking and game mechanics to engage users and solve problems." Similarly, Huotari and Hamari (2012, p. 19) defined gamification as "a process of enhancing a service with affordance for gameful experiences in order to support user's 
overall value creation." This paper adopts one of the most popular definitions of gamification, which was proposed by Deterding, Khaled, et al. (2011, p. 1): gamification is the "use of game design elements in non-game contexts."

Gamification's potential can be applied to areas as distinct as health, sustainability, government, transport, and education (Robson et al., 2015). A key aspect of the gamification process is the fact that it entails the application of various aspects of games design or mechanics with the purpose of improving the user experience. By adding an entertainment component to tasks, the activity is no longer solely instrumental and this motivates user participation (Leaning, 2015). Regardless of its advantages, some skepticism exists around gamification deriving from reports of lack of effectiveness, excessive focus on points and badges, insufficient reward, and absence of central game design elements (Aldemir et al., 2018).

These contradictions in terms of its results began early, when, in despite its growing popularity, in 2012 gamification was placed in the "Peak of Inflated Expectation" by the Gartner Group's Hype Cycle for Emerging Technologies, which predicted that by 2014, $80 \%$ of gamified applications would fail to achieve their business goals (Burke, 2014). The failure of such initiatives may have two explanations: a mismatch between understanding what gamification is, how it works, and how a gamified experience should be designed in order to inspire changes in player behavior (Robson et al., 2015); and a high propagation of the concept and its positive effects, which leads to current expectations exceeding their potential (Burke, 2014). An approach that attempts to address this divergence is the Mechanics, Dynamics and Aesthetics (MDA) Framework (Table 2). This framework constitutes a formal method to understand games and tries to "bridge the gap between game design and development, game criticism, and technical game research... making it easier for all parties to decompose, study and design a broad class of game designs and game artefacts" (Hunicke et al., 2004, p. 1).

\section{Table 2-MDA Framework}

\begin{tabular}{|c|c|}
\hline Component & Description \\
\hline Mechanics & $\begin{array}{l}\text { They are the functional components of the game. They are defined and controlled } \\
\text { by the designers and constitute the various actions, behaviors, and mechanisms } \\
\text { supplied to the players during the game (Hunicke et al., 2004; Zichermann \& Cun- } \\
\text { ningham, 2011). They are defined before the game begins and they are constant for } \\
\text { all the players (Robson et al., 2015). Some of the more known mechanics are virtual } \\
\text { badges, leader boards, points, levels, virtual currencies, virtual goods, avatars, } \\
\text { countdown clocks, questions and challenges, and progress bars (Dicheva et al., } \\
\text { 2015; Kankanhalli et al., 2012). }\end{array}$ \\
\hline
\end{tabular}

Dynamics They relate to the interactions that the players have with the mechanics (Zichermann \& Cunningham, 2011). While the mechanics are established by the designers, the dynamics are the result of how the players interact with the mechanics that have been established (Robson et al., 2015). They describe how each player reacts to each of the mechanics of the system, from the beginning until the end of the game (Hunicke et al., 2004; Zichermann \& Cunningham, 2011).

Aesthetics They concern the emotions invoked by players when they are involved with a game (Hunicke et al., 2004), that is, the result obtained from the interaction between mechanics and dynamics (Zichermann \& Cunningham, 2011). Robson et al. (2015) have argued that aesthetics is more related with computer games, so they've replaced it with emotions and suggested a modified framework, the MDE. According to the authors, emotions are more connected to the engagement effects that can be attained. 
Moreover, it is necessary to examine the important role of gamification in user experience (UX). As Ning (2018) argues, "gamification is an effective design strategy to enhance user experience" (p.114), and it the focus that is placed on motivation and behavioral modification that sometimes overshadows the user experience dimension and how it is affected by gamification initiatives. Although design frameworks are mostly user-centered, not all account for the specific concept of user experience (Mora et al., 2017). Some strategies, using personalized approaches and recommendations, can be deployed within gamification to enhance the user experience, in accordance with different game mechanisms (Klock et al., 2018). It is important to be specific about the type of user experiences that can be created with gamification and how to create them (Sailer et al., 2017). It is important to emphasize that gamification is composed of different elements of game design with diversified applications. In a study conducted by Sailer et al. (2017), the authors used a combination of different game mechanisms to identify the different effect that they would have on the user. They concluded that "badges, leaderboards, and performance graphs positively affect competence need satisfaction, as well as perceived task meaningfulness, while avatars, meaningful stories, and teammates affect experiences of social relatedness" (p. 371). Hence, it is important to predefine what impact is the introduction of game elements expected to have.

In the context of education, gamification is often portrayed as a valuable instrument to improve the students' engagement and motivation and to increase their participation (Leaning, 2015). The key to the effectiveness of gamification in educational settings seems to be a good design and a correct use. Nonetheless, more research is needed to explore the varied array of game elements and their impact on various learning environments (Aldemir et al., 2018). In Dicheva et al.'s (2015) review of relevant studies using gamification in education, the authors identified several game mechanics that can assist learning: points, for student performance; badges, which are attributed following a special accomplishment; progress bars, for indicating the students' progress; leader boards, which represent the students' performance vs. that of their peers; and virtual currency for in-game purchases.

The application of gamification in the education sector is expected to increase as technology becomes more advanced and gamification knowledge grows (Urh et al., 2015). At the same time, previous research in the context of e-Learning has demonstrated the value of gamification, but with limitations to certain aspects of the students' learning process (De-Marcos et al., 2014; Kyewski \& Krämer, 2018; Olsson et al., 2015). As with any technology or strategy that is applied in educational contexts, it is important to always meticulously understand its specificities and the challenges it can pose. Similarly, it is necessary to interpret the different results that are reported in the literature in light of the particular conditions of each experience, as the results are not always explicitly positive/negative, but might be influenced by several factors, not exclusively attributed to design.

\section{E-LEARNING AND GAMIFICATION}

Gamification tools such as avatars, leader boards, and badges can enhance the learning experience of the student (Muntean, 2011), and they can address the lack of motivation that students can experience when they enroll in online learning courses (Olsson et al., 2015). More specifically, gamification can be used in e-learning platforms to enhance engagement (Hassan et al., 2019). E-Learning is characterized mainly by the possibility of learning anytime and anywhere, without spatial or temporal constraints. In addition to its flexibility, e-Learning is associated with personalization, synchronous and asynchronous learning, the acquisition of new competences, independent learning (Lin et al., 2014), wide availability of information (Isaías et al., 2009), and access to technology that promotes digital literacy (Isaías et al., 2013). Peterson et al. (1999) have presented the five Es of E-Learning, which represent the five reasons behind the users' enthusiasm with the e-Learning format delivered over the internet: Exploration, Experience, Engagement, Ease of use, and Empowerment.

The use of online systems for e-Learning offers unlimited possibilities to use innovation, such as gamification, to assist pedagogy (Osipov et al., 2015). As a result, designers have begun to incorporate gamification in e-learning platforms as a strategy to improve engagement and immersiveness 
(Doumanis et al., 2019). The deployment of gamification within online learning environments, can also provide a more adaptive experience to different learners' profiles and thus enhance the attractiveness of e-learning platforms (Alomair \& Hammami, 2020), and assist e-assessment's effectiveness in measuring learners' performance (Zainuddin et al., 2020). E-Learning's core objectives of providing an efficient, effective, engaging, and motivating learning experience can be attained with the support of gamification (Urh et al., 2015). There are several aspects of e-Learning that can be enhanced with gamification. Students can be given the opportunity to use avatars to represent their profile and their progress in the course can be added to a leader board to assess their position in relation to their colleagues. Moreover, it is possible to implement a badge attribution scheme based on certain behaviors (assisting their peers, adding comments) and bonuses can be assigned upon completion of challenging tasks (Muntean, 2011). Additionally, in order to increase motivation and student satisfaction the core learning objectives can be segmented into smaller and more easily accomplished objectives. Student progress should be made clear during the learning process, and it can be illustrated through gamification graphical tools. To increase the students' confidence and motivation, gamification elements can be used to provide positive feedback (Urh et al., 2015).

The literature offers several examples of e-learning platforms that use gamification (Bouchrika et al., 2019; Garcia-Cabot et al., 2020; Karmanova et al., 2019; Ohn et al., 2020; Pesek et al., 2020; Staubitz et al., 2017). There are, equally, various reports of the use of gamification in e-Learning contexts, with varying degrees of effectiveness. In a study by De-Marcos et al. (2014), the authors have assessed the use of gamification and social networking in a learning management system and concluded that, while both tools had a positive impact on academic achievement and students' attitudes, they didn't perform so well in knowledge assessment. Also, Olsson et al. (2015) used progress bars and digital badges in two courses in Moodle and reported that, while progress bars were valuable in providing an overview of the course, their value in improving the completion of the course was difficult to measure. With regards to badges, their motivational effect was different among different groups of students.

The application of badges in an e-learning course was equally studied by Kyewski and Krämer (2018). The students in their study could either receive no badges, receive badges that their peers could see, or receive badges that only they could see. The authors' conclusions have revealed that the badges had less effect on both motivation and performance than it was envisioned. For all three options, over time there was a reduction of intrinsic motivation. Moreover, the badges that were visible only to the student themselves received surprisingly more positive evaluations than those that were shared with their peers. The conclusions of these studies per se might not be as enlightening as educators hope, when using them as templates for their own gamification experience, but they do provide important insight into the different outcomes that design can have on the impact of gamification. In addition, there are factors outside design that can have deep repercussions in the success of gamification. Success, in itself, can be equally difficult to define, as educators will have different objectives and, therefore, different views of success when they design gamification experiences in their course.

\section{METHODS}

In order to assess if the implementation of gamification tools can improve the users' engagement in e-Learning websites, two methods were used: website content analysis of e-Learning websites and an online survey with experts. Websites have become useful research tools, especially due to the fact that they represent rich repositories of data (Pauwels, 2012). The first method was chosen with the objective of providing evidence of the presence or absence of central design elements for engagement and gamification and for engagement indicators on websites. Examining the presence of these three mechanisms is key to provide a primary foundation for this research, as a first stage in determining their importance in the context of online learning. Once this basis was established, the second method was selected to collect the viewpoints of e-Learning and/or gamification experts. The opinions of researchers and educators is key to understanding the different perspectives that exist around 
the core concepts of this research: engagement, gamification, and e-Learning. The online format was preferred for the opportunity it represents of reaching people in different countries in a swift and encompassing manner. Despite their limitations, online surveys have asserted their importance among other research methods, namely for their flexibility, comprehensive reach, swiftness, and ease of data completion (Evans \& Mathur, 2005). The use of these two methods is coherent with the principle of data triangulation (Flick, 2018) and enabled a more comprehensive data collection. Data triangulation as a research strategy can enhance the validity of the results, by means of combing different sources of data (Kern, 2018).

\section{SEARCH AND ANALYSIS OF E-LEARNING WEBSITES}

The e-Learning websites used in this research were gathered from a series of online searches, using Google search engine, with the keywords "e-Learning", "gamification", "best", "sites" and "list". Each search returned hundreds of results, but only 38 were chosen based on two factors: (1) the websites had to be present in the first five pages of the returned results, and (2) had to have an acceptable level of confidence, in compliance with the criteria of accuracy and reliability proposed by the web information sources' assessment form of the University of California Berkeley (2017). After analyzing each of the 38 results, the 15 most popular e-Learning websites, those that appeared more often in the search results, were selected. This selection was conditioned by the keywords used in the search and a series of other determinants that may have biased this list (Bar-Ilan et al., 2009; Goldman, 2011). The classification of most popular is to be interpreted in the context of this specific search. Different search criteria and settings might have yielded a different list. Table 3 lists the final 15 websites used in the analysis.

Table 3 - The 15 e-Learning websites used in the analysis

\begin{tabular}{|c|c|c|}
\hline \multicolumn{2}{|c|}{ E-Learning Websites } & \multirow{2}{*}{$\begin{array}{l}\text { Number of results } \\
20\end{array}$} \\
\hline 1 & Coursera (https://www.coursera.org/L & \\
\hline 2 & EdX (https://www.edx.org/2 & 18 \\
\hline 3 & Khan Academy (https://www.khanacademy.org/2 & 18 \\
\hline 4 & Udemy (https://www.udemy.com/2 & 17 \\
\hline 5 & Codecademy (https://www.codecademy.com/2 & 16 \\
\hline 6 & MIT OpenCourseWare (https://ocw.mit.edu/index.htm) & 11 \\
\hline 7 & ALISON (https://alison.com/2 & 10 \\
\hline 8 & Duolingo (https://www.duolingo.com// & 10 \\
\hline 9 & Academic Earth (http://academicearth.org// & 8 \\
\hline 10 & Open Culture (http://www.openculture.com/2 & 8 \\
\hline 11 & Open Yale Courses (http://oyc.yale.edu/2 & 8 \\
\hline 12 & Udacity (https://www.udacity.com/2 & 8 \\
\hline 13 & $\begin{array}{l}\text { Carnegie Mellon Open Learning Initiative } \\
\text { (http://oli.cmu.edu/2 }\end{array}$ & 7 \\
\hline 14 & $\begin{array}{l}\text { Open Learn - Open University (http://www.open.edu/open- } \\
\text { learn/2 }\end{array}$ & 6 \\
\hline 15 & Skillshare (https://www.skillshare.com/) & 6 \\
\hline
\end{tabular}


Once the sample was defined, a detailed analysis of each website was conducted. This analysis was based on the observation of several elements, subdivided into three categories: gamification elements, previously presented in the gamification section; key elements for engagement in the websites, presented and defined in Table 1; and engagement indicators on the websites, as described above.

\section{SURVEY}

The survey that was created for the purpose of this study was divided into three parts. The first part aggregated all the questions related to demographics and other aspects of the respondents' profiles. The second one intended to examine the respondents' familiarity with the concepts of this study and to understand the relevance that they attribute to such concepts. Finally, the third part was designed to provide a deeper insight into each concept and the relation between them. The first two parts of the survey were composed mostly of closed-ended and multiple-choice questions, making up about half of the questionnaire. The latter part included multiple-choice, Likert-scale, and some open-ended questions. The survey also allowed the respondents to leave additional comments about the topic under discussion and to evaluate the content of the survey. The survey was designed on the online platform Qualtrics and it was distributed by email.

Since the survey required some theoretical knowledge about the topics in question, the sample of respondents was composed of experts in the e-Learning and/or gamification fields. To ensure that the survey provided an international perspective, experts from several countries were invited to participate by means of both convenience sampling, which despite being a nonprobability sampling with limitations, it is a valuable method namely in cases where randomization is not possible (Etikan et al., 2016), and purposive sampling (Lavrakas, 2008). Nonprobability sampling approaches can equally be applicable in situations where no sampling frame exists (Isaías et al., 2012). Thus, the sample was constituted by international contacts that were easily accessible to the researchers and who were invited to participate because of their expertise in e-learning/gamification.

\section{ANALYSIS OF THE RESULTS}

\section{RESPONDENTS CHARACTERIZATION}

The online survey was sent to 1050 individuals and received 237 valid responses. From the total of respondents, $61 \%$ are male and 39\% are female, mostly in the 30-50 age range (Figure 1) and with a high educational level $(67 \%$ have a $\mathrm{PhD})$, as it is shown in Figure 2. The survey obtained responses from 56 different countries, with the highest number of answers coming from the following countries: Brazil (11\%); United States of America (11\%); Germany (8\%); Spain (8\%); United Kingdom (8\%); Australia (6\%); Canada (5\%); Greece (3\%); and Malaysia (3\%).

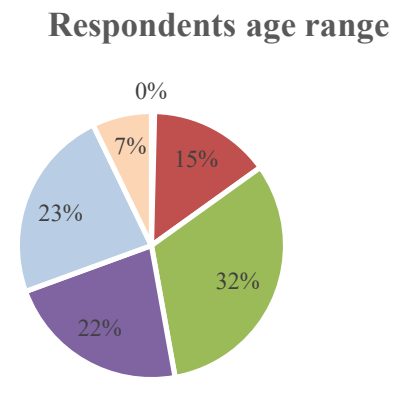

Figure 1- Respondents age range

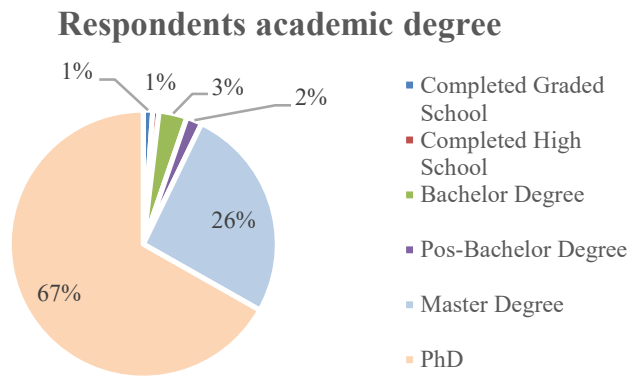

Figure 2 - Respondents academic degree 
Regarding the professional activities of the respondents, $37 \%$ of them are researchers and $36 \%$ are teachers (Figure 3). Their knowledge areas are mainly computer sciences (31\%), education (24\%), and information technologies (21\%), as it is illustrated in Figure 4.

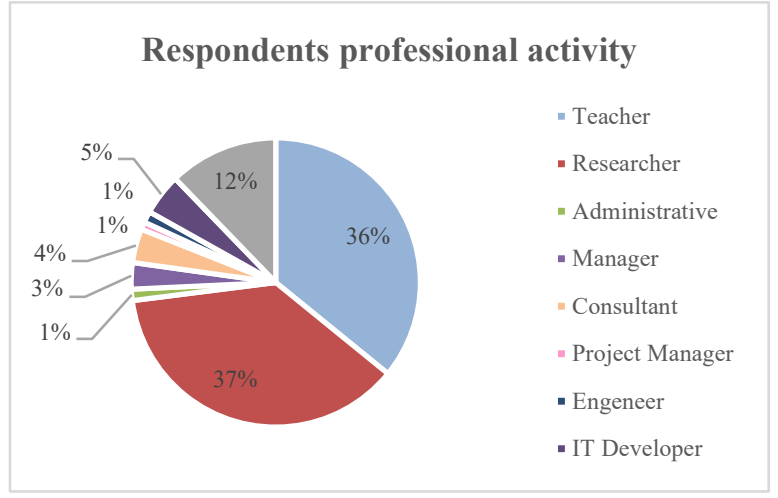

Figure 3 - Respondents professional activity

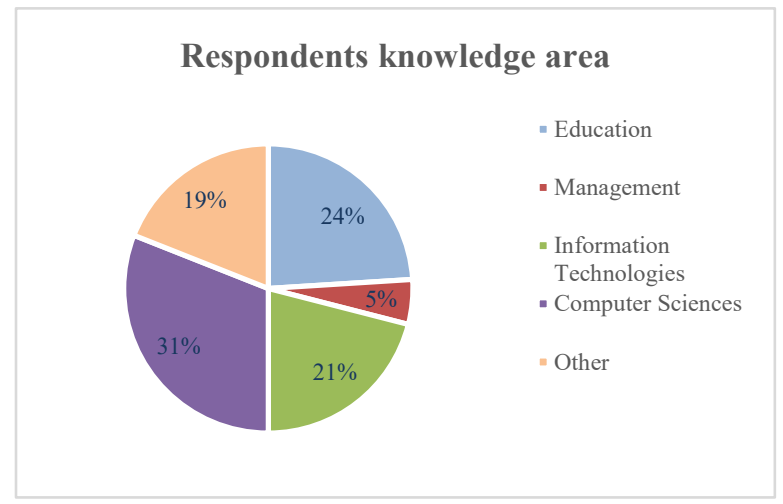

Figure 4 - Respondents knowledge area

Most of the respondents know the concepts covered in this study because they have already experienced them in the first person: $85 \%$ of the respondents already had an experience with gamification, $96 \%$ already had an e-Learning experience, and most of the gamification experiences were lived online $(90 \%)$ and due to educational, professional, or personal concerns.

The respondents considered that gamification and engagement are current and relevant study areas ( $92 \%$ and $86 \%$ respectively). Also, they stated that these two areas can be studied together, since gamification is an area with a broad range of applications and can be used to increase player/user/consumer engagement. Moreover, almost all of the respondents (98\%) agreed that gamification can be used to increase engagement in e-Learning websites and, given the choice for five reasons (the 5 E's of e-Learning) that might induce enthusiasm in a gamified e-Learning experience, most respondents chose engagement.

\section{USE OF GAMIFICATION ELEMENTS}

In the analysis of the e-Learning websites, via observation, the elements of gamification were considered. Based on these indicators, the analysis of the main 15 websites listed in Table 3 , showed that that most of the e-Learning websites $(80 \%)$ apply gamification tools. The most commonly used gamification elements are levels (73\%), questions and challenges (67\%), and progress bars $(67 \%)$, as it is shown in Figure 5. On the contrary, the less used ones are leader boards $(0 \%)$, badges $(13 \%)$, and other tools (13\%), including virtual currencies, virtual goods, and countdown clocks (Figure 5). 


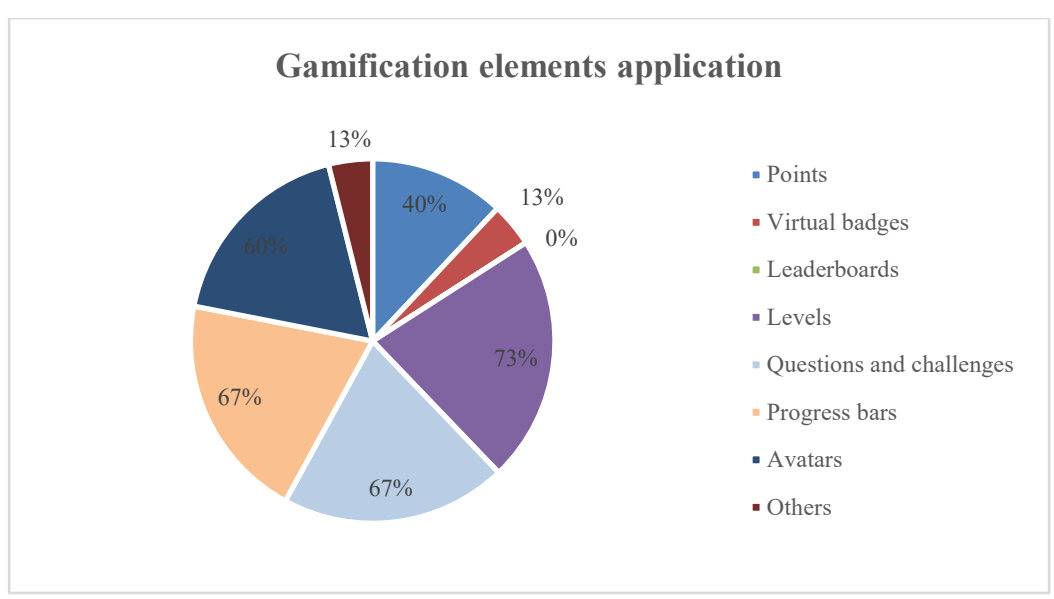

Figure 5-Gamification elements application

Since these results show that the selected e-Learning websites are indeed applying gamification tools, the next step involved examining if the tools that are being applied by the websites are the most effective. To determine if the tools are having an ultimate positive effect on the users' engagement, a question was included on the survey, asking the participants to classify gamification tools according to their effectiveness to the users' engagement in e-Learning websites. They were required to use a scale from 1 to 5 (1- no effectiveness at all, 5 - critical effectiveness). With the application of the statistical analysis one-way ANOVA, which is a statistical method that tests the equality hypothesis between two or more means (Lane et al., 2014), the null hypothesis of means equality can be rejected $(p<0.05)$. This means that each gamification element has a different impact on the users' engagement. Hence, according to the respondents, the most effective gamification elements are, in descending order of averages, questions and challenges (4.095 \pm 0.877$)$, levels $(3.915 \pm 0.873)$, and progress bars $(3.915 \pm 0.96)$. The elements that the experts highlighted as being more effective correspond to the elements that were more abundantly used by the selected e-Learning websites, as illustrated in Figure 5. Similarly, the elements that were used the least by the websites (Figure 5), were listed by the respondents as the least effective, which are, in descending order of averages, avatars $(3.135 \pm 1.04)$, leaderboards $(3.5 \pm 1.008)$, and badges $(3.61 \pm 0.955)$. Here, it is important to note that avatars constitute an exception. Despite being listed among the least effective by the respondents, avatars were among the elements that the websites used the most. Regardless of this exception, according to the viewpoint of the participants, the sample of e-Learning websites that was analyzed is mainly using effective gamification elements.

Since, it is common to apply several elements of gamification at the same time, the correlation between the variables must be observed, which indicates the degree of linear relation between them (Lane et al., 2014) and allows the measurement of which elements of gamification used together can offer greater effectiveness in obtaining users' engagement. The correlation coefficients that were obtained are all positive and close to 1 , which means that there is a positive linear relationship between the variables and that this relation is strong. The combinations that provide greater joint effectiveness (Table 4) are, in descending order, points and virtual badges $(r=0.959 ; n=200 ; p=0.05)$; levels and progress bars $(r=0.945 ; n=200 ; p=0.05)$; virtual badges and leaderboards $(r=0.94 ; n=$ $200 ; p=0.05)$; questions and challenges and avatars $(r=0.927 ; n=200 ; p=0.05)$; points and leader boards $(r=0.921 ; n=200 ; p=0.05)$; progress bars and avatars $(r=0.917 ; n=$ $200 ; p=0.05)$. The analysis of the sampled e-Learning websites shows that only half of these elements combinations are being applied more frequently: levels and progress bars; questions and challenges and avatars; and progress bars and avatars. 
Gamification as an Engagement Tool

Table 4- Gamification elements effectiveness: Correlation

\begin{tabular}{llllllll}
\hline & Points & $\begin{array}{l}\text { Virtual } \\
\text { badges }\end{array}$ & $\begin{array}{l}\text { Leader } \\
\text { boards }\end{array}$ & Levels & $\begin{array}{l}\text { Questions } \\
\text { and chal- } \\
\text { lenges }\end{array}$ & $\begin{array}{l}\text { Progress } \\
\text { bars }\end{array}$ & Avatars \\
\hline Points & 1 & & & & & \\
Virtual badges & 0.959 & 1 & & & & \\
Leader boards & 0.921 & 0.940 & 1 & & & \\
Levels & 0.894 & 0.876 & 0.872 & 1 & & \\
Questions and & & & & & & 1 \\
Challenges & 0.854 & 0.854 & 0.873 & 0.903 & 1 & \\
Progress bars & 0.903 & 0.884 & 0.875 & 0.945 & 0.916 & 1 \\
Avatars & 0.878 & 0.878 & 0.889 & 0.909 & 0.927 & 0.917 & 1 \\
\hline
\end{tabular}

From the previous analysis, three conclusions can be drawn: (1) leader boards have little effectiveness and little use singularly, but are valued when joined with other elements (e.g., virtual badges and points); (2) avatars only become useful when applied with at least one other tool; (3) all other elements are being properly applied, since the most used elements are precisely the most effective ones.

Although this study focused solely on the main gamification elements, through an open question in the survey, the respondents also highlighted the importance of other elements such as feedback, clear goals, interaction between users, opportunity to fail, and the existence of a narrative/story.

\section{USE OF ENGAGEMENT ELEMENTS}

The analysis of the websites confirms the strong presence of engagement elements in e-Learning websites. The engagement elements that are more frequently applied are purpose $(100 \%)$, content utility $(100 \%)$, readability $(93.3 \%)$, simplicity $(93.3 \%)$ and navigation $(93.3 \%)$. Those that are less frequently applied still had significant or high percentages: social media integration (60\%), graphical representation (73.3\%), organization and compatibility with several devices and browsers $(86.6 \%)$. Even the websites that have fewer engagement elements include more than half of the presented elements (7 out of 10), as can be seen in Figure 6.

Following the website analysis, it was important to assess the effectiveness of the engagement elements for users' engagement from the perspective of the respondents, who were asked to classify them using a scale from 1 to 5 (1- no effectiveness at all, 5 - critical effectiveness). Considering the statistical analysis one-way ANOVA, since $p<0.5$, it is possible to reject the null hypothesis of means equality and conclude that the engagement elements do not have the same impact on the users engagement effectiveness. In this case, it is extremely important to perceive which elements are more impactful. 


\section{Application of engagement elements}

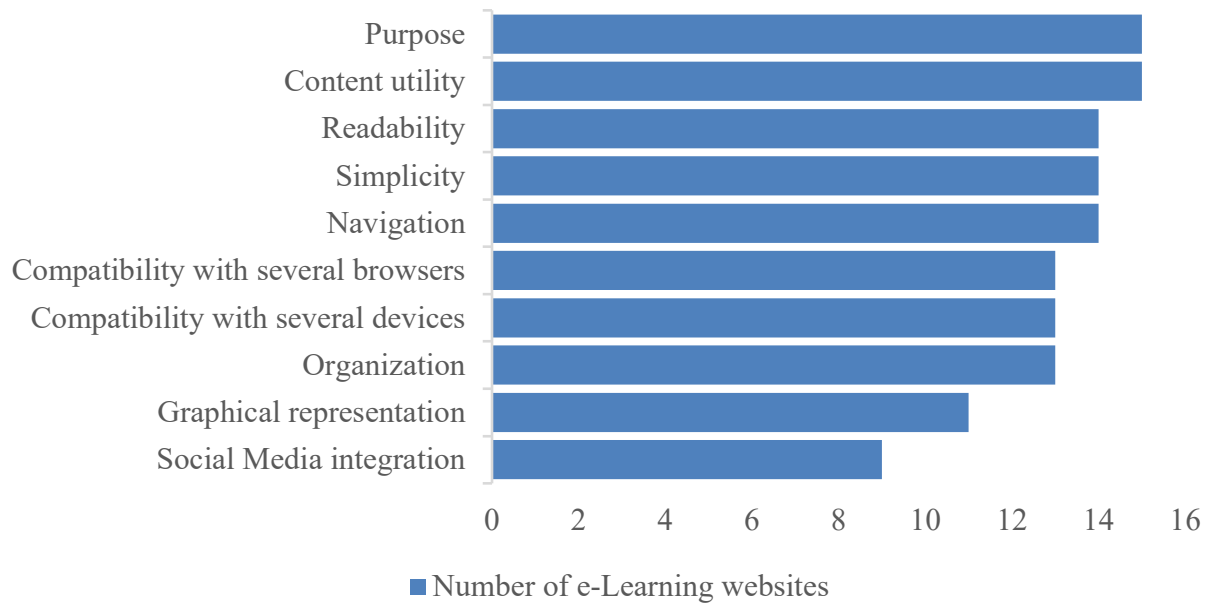

Figure 6 - Number of e-Learning website with engagement elements

The elements that are considered more effective to create users' engagement are, in descending order of averages, readability ( $4.236 \pm 0.752)$; purpose ( $4.211 \pm 0.776)$; content utility (4.156 \pm $0.786)$; and simplicity $(4.131 \pm 0.812)$. Similar to what occurred with the gamification elements, the experts opinions about the most effective engagement elements correspond to those more frequently applied by the selected e-Learning websites. On the contrary, the elements considered to be less effective for users' engagement are, according to the obtained averages, compatibility with several devices (3.930 \pm 0.946$)$; compatibility with several browsers ( $3.839 \pm 1.022)$; and social media integration $(3.322 \pm 1.028)$ - Table 5 . In this case and despite the opinion of the respondents, which was less favorable towards these elements, they were frequently present on the sampled websites. Although they did rank in the lower percentages.

Table 5 - Engagement elements effectiveness: Descriptive Statistics

\begin{tabular}{llllll}
\hline Element & Mean & Mode & Median & $\begin{array}{l}\text { Standard Devi- } \\
\text { ation }\end{array}$ & $\begin{array}{l}\text { Sample Var- } \\
\text { iance }\end{array}$ \\
\hline Navigation & 4.121 & 4 & 4 & 0.807 & 0.652 \\
Graphical representation & 4.030 & 4 & 4 & 0.765 & 0.585 \\
Organization & 4.050 & 4 & 4 & 0.783 & 0.614 \\
Content utility & 4.156 & 4 & 4 & 0.786 & 0.617 \\
Purpose & 4.211 & 4 & 4 & 0.776 & 0.602 \\
Simplicity & 4.131 & 4 & 4 & 0.812 & 0.66 \\
Readability & 4.236 & 4 & 4 & 0.752 & 0.565 \\
$\begin{array}{l}\text { Compatibility with several de- } \\
\text { vices }\end{array}$ & 3.839 & 4 & 4 & 1.022 & 1.045 \\
$\begin{array}{l}\text { Compatibility with several } \\
\text { browsers }\end{array}$ & 3.930 & 4 & 4 & 0.946 & 0.894 \\
Social Media integration & 3.322 & 3 & 3 & 1.028 & 1.058 \\
\hline
\end{tabular}


As these elements are not applied individually, it is valuable to understand which of them, when used together, can produce a more positive effect in the connection between the user and the website. For this effect, it is possible to analyze the correlation between variables. Based on this analysis, the elements that can lead to a better joint effectiveness are, in descending order, simplicity and content utility $(r=0.981 ; n=199 ; p=0.05)$; organisation and graphical representation $(r=0.967 ; n=$ 199; $p=0.05)$; compatibility with several devices and compatibility with several browsers $(r=$ $0.96 ; n=199 ; p=0.05)$; purpose and content utility $(r=0.949 ; n=199 ; p=0.05)$; simplicity and navigation $(r=0.946 ; n=199 ; p=0.05)$; and simplicity and organization $(r=0.942 ; n=$ $199 ; p=0.05)$.

From the above analysis, one can conclude that (1) there are elements that demonstrate to be important when used both individually and collectively, such as simplicity, content utility, and organization and (2) there are elements that have very little individual effectiveness, but that reveal their potential when used collectively, such as compatibility with several devices and compatibility with several browsers.

\section{ENGAGEMENT METRICS}

The engagement metrics were used both in the analysis of the e-Learning websites and in the survey design. The survey also included a new metric, percentage of completed courses. Some of the metrics have previously calculated values that were presented by Alexa (2017). From the total of metrics, only two (daily page views per visitor and daily time on site) were conclusive when used to relate the number of applied gamification and engagement elements and the engagement level of the users. Thus, eLearning websites that apply gamification and engagement elements have, on average, a greater number of daily views, with the highest values belonging to ALISON (7.83) and EdX (6.09) and a longer daily time on site, with the highest durations also belonging to ALISON (13:16) and $\operatorname{EdX~(07:32).~}$

In the survey, the participants were asked to rate the engagement metrics according to their importance to measuring users' engagement in e-Learning websites, using a scale from 1 to 5 (1- not important at all, 5- extremely important. The application of the statistical analysis one-way ANOVA reveals that $p<0.05$. In this case, the null hypothesis of means equality can be rejected, which means that the engagement indicators do not have the same importance level. In descending order, the engagement metrics considered as most important are percentage of completed courses (4.035 \pm $0.899)$; frequency $(3.805 \pm 0.923)$; and rating $(3.635 ; 1.018)$ - Table 6 . This means that, although the indicators provided by Alexa (2017) are better described and are easier to measure quantitatively, they are considered to be less relevant by the survey respondents. From all the Alexa (2017) metrics, the participants' highlighted daily time on site $(3.590 \pm 0.978)$ as the most important.

As in the previous sub-section, and given that the degree of users' engagement for a particular website is measured by a set of metrics, it is of interest to observe the indicators that, when used together, provide a better measurement of engagement. For this purpose, an analysis of their correlation was performed. The following correlations can be observed, in descending order: percentage of traffic from search and percentage of sites linking in $(r=0.982 ; n=200 ; p=0.05)$; virality and bouce rate $(r=0.972 ; n=200 ; p=0.05)$; bounce rate and daily page views per visitor $(r=$ $0.970 ; n=200 ; p=0.05)$; virality and daily pageviews per visitor $(r=0.960 ; n=200 ; p=$ $0.05)$; daily time on site and rating $(r=0.959 ; n=200 ; p=0.05)$; and virality and recency $(r=0.932 ; n=200 ; p=0.05)$. 
Table 6 - Engagement metrics importance: Descriptive statistics

\begin{tabular}{llllll}
\hline Element & Mean & Mode & Median & $\begin{array}{l}\text { Standard } \\
\text { Deviation }\end{array}$ & $\begin{array}{l}\text { Sample } \\
\text { Variance }\end{array}$ \\
\hline Daily time on site & 3.590 & 4 & 4 & 0.978 & 0.967 \\
$\begin{array}{l}\text { Daily page views per } \\
\text { visitor }\end{array}$ & 3.150 & 3 & 3 & 1.001 & 1.003 \\
Bounce rate & 3.215 & 3 & 3 & 1.017 & 1.034 \\
\% traffic from search & 2.870 & 2 & 3 & 1.100 & 1.209 \\
Total sites linking in & 2.835 & 3 & 3 & 1.093 & 1.194 \\
\% completed courses & 4.035 & 4 & 4 & 0.899 & 0.808 \\
Recency & 3.400 & 3 & 3 & 0.877 & 0.770 \\
Frequency & 3.805 & 4 & 4 & 0.923 & 0.851 \\
Virality & 3.240 & 3 & 3 & 1.076 & 1.158 \\
Rating & 3.635 & 4 & 4 & 1.018 & 1.037 \\
\hline
\end{tabular}

Besides the engagement metrics that were listed, the respondents suggested other indicators that they considered as being important: user feedback, achievement of objectives, purpose of the activity, and satisfaction surveys.

\section{MULTI-LINEAR REGRESSION}

This analysis described in this section derives from the need to relate the previous sections and to reduce the elements of gamification and the engagement elements and metrics to uncover the factors that actually result in the best levels of users' engagement in e-Learning websites using gamification. Only the most important metrics were studied and, for each one, a multi-linear regression model was created. A hypothesis test was then applied to the coefficients of this model. The multi-linear regression model allows the prediction of the behavior of a dependent variable through two or more independent variables (Lane et al., 2014). In this particular case it allows one to predict the behavior of the metrics percentage of completed courses, frequency, rating, and daily time on site, through the elements of gamification and engagement.

The hypothesis tests on the coefficients allow reducing the model only to the independent variables with statistical relevance to explain each one of the dependent variables. It is intended to take the generic model (shown below) with all the restrictions and to remove individually the variables with the highest $p-$ value, until the moment when there is no variable with a $p>0.05$. It is in this moment that all the present variables in the model are essential to explain it, thus obtaining a reduced model.

Starting with the indicator percentage of completed courses:

\section{Generic model:}

$$
\begin{aligned}
P C C=0.07+ & 0.265 N a v+0.231 G R-0.132 O-0.127 C U-0.131 P u r p+0.294 S-0,01 R \\
& -0.066 C B+0.15 C D+0.04 S M I+0.021 P-0.027 V B-0.055 L-0.096 \text { Lev } \\
& +0.342 Q C+0.202 P B+0.105 A
\end{aligned}
$$




\section{Reduced model:}

$P C C=0.133+0.284 N a v-0.23 P u r p+0.197 S+0.419 Q C+0.219 P B+0.101 A$

\section{Legend:}

PCC - Percentage of completed courses; Nav - Navigation; GR - Graphical representation; O - Organization; CU - Content utility; Purp - Purpose; S - Simplicity; R - Readability; CB - Compatibility with several browsers; CD - Compatibility with several devices; SMI - Social Media integration; P - Points; VB - Virtual badges; L - Leader boards; Lev - Levels; QC - Questions and challenges; PB - Progress bars; A - Avatars

The variables that best explain the percentage of complete courses are navigation, purpose, simplicity, questions and challenges, progress bars, and avatars. An increase in the use of all of the variables, except purpose, positively influences the dependent variable percentage of complete courses. On the other hand, purpose negatively influences the dependent variable. It is also possible to observe that four of the variables were classified as being the most effective gamification and engagement elements (purpose, simplicity, questions and challenges, and progress bars) and only one of them (avatars) was less effective. However, as it was seen earlier, this indicator may prove to be useful when used in combination with others.

Relatively to the indicator frequency, the following reduced model was generated:

$F=0.011+0.199 C B+0.387 C D+0.319 P+0.504 L e v-0.417 P B$

It is important to note that the gamification and engagement tools that best explain this model are compatibility with several browsers, compatibility with several devices, points, levels, and progress bars. The first three elements positively influence the access frequency to e-Learning websites using gamification, and the progress bars have a negative influence. From these elements, only levels and progress bars belong to the most effective elements, being responsible for higher levels of users' engagement. This is coherent with the reduced model, since these two variables are also the ones that influence the greater results in the dependent variable frequency.

Using the multi-linear regression model with respect to the rating metric, the following reduced model was obtained:

$R=-0.382-0.267 C U+0.324 S+0.241 P+0.65 V B-0.141 L e v$

The tools that best explain this model are content utility, simplicity, points, virtual badges, and levels. Some of these elements (simplicity, points, and virtual badges) have a positive influence in explaining the dependent variable rating, while others (content utility and levels) have a negative influence. Also, it is possible to observe that three of the five variables that explain this model belong to the most effective elements (content utility, simplicity, and levels), and one of these variables belongs to the group of less effective elements (virtual badges).

With concern to the last engagement metric, daily time on site, it was possible to obtain the reduced model below:

$T M U=0.075+0.101 C B+0.282 P+0.597 L$

This model is explained by only three variables (compatibility with several browsers, points, and leader boards) and none of these elements is one of the most effective for promoting users' engagement. One of them (leader boards) belongs to the group of less effective elements, although this is an effective element when used collectively.

In conclusion, there were some elements that did not appear in any of the models, due to their lack of statistical relevance to explain the presented engagement metrics. These elements were graphic representation, organization, readability, and social media integration. It is interesting to note that all 
the gamification elements have statistical relevance to explain at least one of the metrics. The elements that have presence in more than one model are levels, progress bars, compatibility with several browsers, and points. Hence, with this study it is possible to prove the existence of a relationship between the use of gamification tools and the degree of engagement. This relationship is positive, in the sense that most of the elements of gamification positively influence engagement metrics.

\section{DISCUSSION}

The results made evident that there is a positive correlation between the use of gamification tools and the degree of users' engagement in an e-learning website. The majority of the e-Learning websites use gamification and engagement elements, which is in line with the tendency expressed by previous studies (Bouchrika et al., 2019; Doumanis et al., 2019; Garcia-Cabot et al., 2020; Karmanova et al., 2019; Ohn et al., 2020; Pesek et al., 2020; Staubitz et al., 2017). In addition, the elements that are more commonly used are also the most effective, according to the opinions of the experts. Thus, not only do e-Learning websites use gamification and engagement tools, but, in the view of the respondents, they equally use the tools that more positively impact their users' engagement. Prospectively, it would be valuable to triangulate this information with data collected from the experts regarding their own experience in creating gamification initiatives and the results that they obtain with these and other specific gamification elements.

An important conclusion that derived from the results pertains to the fact that these elements, both for engagement and gamification, have an influence on engagement when used individually or simultaneously with other elements. Avatars, leader boards, and compatibility with several devices and browsers individually do not have much impact on users' engagement, but their importance is revealed when they are applied with other tools. These results are coherent with what was argued by Sailer et al. (2017) when describing gamification as a combination of different elements of game design with differentiated applications that produce diverse effects on the users. This places an emphasis on the importance of gamification design and avoids some of the practices that previous studies have identified as detrimental (Aldemir et al., 2018), such as excessively incorporating points and badges and restricting reward systems and core game design instruments. Hence, depending on the purpose of the experience, different mechanisms should be used to elicit the intended affect.

In accordance with Zichermann and Cunningham (2011), who had already posited that user engagement on websites needs to be measured by interconnected metrics, the results showed some suitable indicators. Nonetheless, with concern to the engagement metrics that best quantify the degree of engagement between the user and the e-Learning website, the conclusions were not as definite as was expected. Only the indicators daily page views per visitor and daily time on site were conclusive in terms of their connection to gamification and engagement elements. According to the analysis of the websites, those who applied gamification and engagement elements have, on average, a greater number of daily views and daily time on site.

However, a reduction was achieved of four key indicators: percentage of completed courses, frequency, rating, and daily time on site. It was equally possible to draw two conclusions from the relationship between the gamification and the engagement elements and the metrics, which underline the potential of gamification to enhance student engagement, as was argued previously by the literature (Doumanis et al., 2019; Hassan et al., 2019; Leaning, 2015). Firstly, the websites that use more gamification tools are the ones with the highest values for the announced metrics. Secondly, there is a positive relation between them, in the sense that the application of more gamification and engagement elements results in the increase of the degree of engagement. Garett et al. (2016) had already in their research highlighted that the impact of these elements of website design on engagement varies proportionally to the number of elements that are used. This can be a valuable conclusion in terms of the design of gamification experiences that are created with the specific purpose of enhancing engagement. According to the results, when the main objective of the introduction of a gamification initiative in e-Learning is the promotion of the learners engagement, deploying more game elements 
will be more beneficial. These aspects of user interface (UI) are important to positively influence and forecast user engagement. Their impact is greater as more elements are applied.

\section{CONCLUSION}

This paper aimed to explore the connection that exists between the use of gamification tools and the degree of users' engagement in e-Learning websites and to determine the nature of that connection, by examining e-Learning websites and consulting experts via an online survey. The results provided a clear depiction of that connection and offered important insight in terms of the application of gamification and engagement elements within e-Learning websites. It became clear from the triangulation of the data that certain elements of gamification produce more effective results where engagement is concerned. Similarly, the presence of engagement elements on e-Learning websites has positive repercussion on the engagement of the students with the platform. Not only are these websites resorting to engagement and gamification elements as a strategy to improve the engagement of their users, but they are doing so successfully.

The findings from the data analysis are relevant for both researchers and practitioners. From a research perspective, these findings add to a growing body of studies that focus on the benefits of gamification by highlighting its positive repercussions on engagement and identifying which elements are more effective. In addition, the use of different sources of data provided a wider illustration of what is currently the use of gamification elements by functioning e-Learning websites and how those who apply them in practice in their courses perceive these elements. From a practitioner's viewpoint it can assist both learning designers and teachers in the creation of gamification strategies to enhance students' engagement. As a central challenge of e-Learning course, engagement requires a multifaceted approach to be addressed effectively and knowing the strategies that have positive outcomes is a step forward in ensuring the students can enroll in online courses and not be compromised with respect to their engagement. Finally, the lack of engagement can have serious repercussions not only on the learning experience of the students, but also on their actual academic performance. Hence, it is important to guide educators towards good design practices that can maximize engagement in these settings.

This study's main limitations concern the high non-response rate to the online questionnaire and the fact that the participants were selected via convenience sampling, preventing these findings from being generalizable. Gamification is an important field that is progressively asserting its importance and that transverses several areas. Future research can use these results to explore the use of gamification as a tool of engagement in other areas, namely in business, resorting to different metrics and indicators. Additionally, within the education sector, further research can be conducted to assess the students' perceptions of the value of gamification and its potential to impact their learning performance. Understanding the viewpoints of students is critical to developing an encompassing depiction of gamification in higher education, as they are at the center of its deployment.

\section{REFERENCES}

Aguiar, E., Ambrose, G. A. A., Chawla, N. V., Goodrich, V., \& Brockman, J. (2014). Engagement vs performance: Using electronic portfolios to predict first semester engineering student persistence. Journal of Learning Analytics, 1(3), 7-33. https://doi.org/10.18608/jla.2014.13.3

Aldemir, T., Celik, B., \& Kaplan, G. (2018). A qualitative investigation of student perceptions of game elements in a gamified course. Computers in Human Behavior, 78, 235-254. https://doi.org/10.1016/j.chb.2017.10.001

Alexa. (2017). The Top 500 sites on the Web. Retrieved 20-05-2017 from https://www.alexa.com/topsites

Alomair, Y., \& Hammami, S. (2020, 19-21 March 2020). A review of methods for adaptive gamified learning environments. 2020 3rd International Conference on Computer Applications \& Information Security (ICCAIS), IEEE. https://doi.org/10.1109/iccais48893.2020.9096871 
Bar-Ilan, J., Keenoy, K., Levene, M., \& Yaari, E. (2009). Presentation bias is significant in determining user preference for search results-A user study. Journal of the American Society for Information Science and Technology, 60(1), 135-149. https://doi.org/10.1002/asi.20941

Bawa, P. (2016). Retention in online courses: Exploring issues and solutions-A literature review. Sage Open, 6(1). https://doi.org/10.1177/2158244015621777

Bouchrika, I., Harrati, N., Wanick, V., \& Wills, G. (2019). Exploring the impact of gamification on student engagement and involvement with e-learning systems. Interactive Learning Environments, 1-14. https://doi.org/10.1080/10494820.2019.1623267

Burke, B. (2014). Gamify: How gamification motivates people to do extraordinary things. Bibliomotion. https://doi.org/10.4324/9781315230344

De-Marcos, L., Domínguez, A., Saenz-de-Navarrete, J., \& Pagés, C. (2014). An empirical study comparing gamification and social networking on e-learning. Computers \& Education, 75, 82-91. https://doi.org/10.1016/j.compedu.2014.01.012

Deterding, S., Dixon, D., Khaled, R., \& Nacke, L. (2011). From game design elements to gamefulness: Defining gamification. In Proceedings of the 15th international academic MindTrek conference: Envisioning future media environments (pp. 9-15). ACM. https://doi.org/10.1145/2181037.2181040

Deterding, S., Khaled, R., Nacke, L. E., \& Dixon, D. (2011). Gamification: Toward a definition. In Proceedings of the ACM CHI Conference on Human Factors in Computing Systems (Vol. 12, pp. 1-4). Vancouver BC, Canada. http://gamification-research.org/wp-content/uploads/2011/04/02-Deterding-Khaled-Nacke-Dixon.pdf

Dicheva, D., Dichev, C., Agre, G., \& Angelova, G. (2015). Gamification in education: A systematic mapping study. Journal of Educational Technology \& Society, 18(3), 75-88. http://www.jstor.org/stable/jeductechsoci.18.3.75

Doumanis, I., Economou, D., Sim, G. R., \& Porter, S. (2019). The impact of multimodal collaborative virtual environments on learning: A gamified online debate. Computers \& Education, 130, 121-138. https://doi.org/10.1016/j.compedu.2018.09.017

Etikan, I., Musa, S. A., \& Alkassim, R. S. (2016). Comparison of convenience sampling and purposive sampling. American Journal of Theoretical and Applied Statistics, 5(1), 1-4. https://doi.org/10.11648/j.ajtas.20160501.11

Evans, J. R., \& Mathur, A. (2005). The value of online surveys. Internet Research, 15(2), 195-219. https://doi.org/10.1108/10662240510590360

Flick, U. (Ed.). (2018). The SAGE handbook of qualitative data collection. SAGE Publications. https://doi.org/10.4135/9781526416070.

Garcia-Cabot, A., Garcia-Lopez, E., Caro-Alvaro, S., Gutierrez-Martinez, J. M., \& de-Marcos, L. (2020). Measuring the effects on learning performance and engagement with a gamified social platform in an MSc program. Computer Applications in Engineering Education, 28(1), 207-223. https://doi.org/10.1002/cae.22186

Garett, R., Chiu, J., Zhang, L., \& Young, S. D. (2016). A literature review: Website design and user engagement. Online Journal of Communication and Media Technologies, 6(3), 1-14. https://doi.org/10.29333/ojcmt/2556

Georgakopoulos, I., Kytagias, C., Psaromiligkos, Y., \& Voudouri, A. (2018). Identifying risks factors of students' failure in e-learning systems: Towards a warning system. International Journal of Decision Support Systems, 3(3-4), 190-206. https://doi.org/10.1504/ijdss.2018.10021896

Goldman, E. (2011). Revisiting search engine bias. William Mitchell Law Review, 38, 96.

Hassan, M. A., Habiba, U., Majeed, F., \& Shoaib, M. (2019). Adaptive gamification in e-learning based on students' learning styles. Interactive Learning Environments, 1-21. https://doi.org/10.1080/10494820.2019.1588745

Henrie, C. R., Halverson, L. R., \& Graham, C. R. (2015). Measuring student engagement in technology-mediated learning: A review. Computers \& Education, 90, 36-53. https://doi.org/10.1016/j.compedu.2015.09.005 
Gamification as an Engagement Tool

Hunicke, R., LeBlanc, M., \& Zubek, R. (2004). MDA: A formal approach to game design and game research. In Proceedings of the AAAI Workshop on Challenges in Game AI (Vol. 4, pp. 1-5). AAAI Press San Jose, CA. https://www.aaai.org/Papers/Workshops/2004/WS-04-04/WS04-04-001.pdf

Huotari, K., \& Hamari, J. (2012). Defining gamification: a service marketing perspective. In Proceeding of the 16th international academic MindTrek conference (pp. 17-22). ACM. https://doi.org/10.1145/2393132.2393137

Hussain, M., Zhu, W., Zhang, W., \& Abidi, S. M. R. (2018). Student engagement predictions in an e-learning system and their impact on student course assessment scores. Computational intelligence and neuroscience, 2018, Article ID 6347186. https://doi.org/10.1155/2018/6347186

Isaías, P., Miranda, P., \& Pifano, S. (2009). Towards an effective e-learning 2.0. In Proceedings of the 1st International Conference on Education and New Learning Technologies (EDULEARN 09) (pp. 4997-5004). IATED.

Isaías, P., Miranda, P., \& Pifano, S. (2013). Digitally literate: Framework for the development of digital literacy. In B. White \& P. Isaías (Eds.), Proceedings of the IADIS International Conference Www/Internet. (pp. 277-282). IADIS Press

Isaías, P., Pifano, S., \& Miranda, P. (2012). Subject recommended samples: Snowball sampling. In P. Isaías \& M. Baptista Nunes (Eds.), Information systems research and exploring social artifacts: Approaches and methodologies (pp. 43-57). IGI Global. https://doi.org/10.4018/978-1-4666-2491-7.ch003

Kankanhalli, A., Taher, M., Cavusoglu, H., \& Kim, S. H. (2012). Gamification: A new paradigm for online user engagement. In Thirty Third International Conference on Information Systems: "Digital Innovation in the Service Economy” (pp. 1-10). Association for Information Systems. https://aisel.aisnet.org/icis2012/proceedings/ResearchInProgress $/ 7 /$

Karmanova, E., Chernova, E., \& Dokolin, A. (2019). Modeling knowledge assessment with gamification technology on e-learning platform. 2019 International Multi-Conference on Industrial Engineering and Modern Technologies (FarEastCon), Vladivostok, Russia, pp. 1-6. https://doi.org/10.1109/fareastcon.2019.8934089

Kern, F. G. (2018). The trials and tribulations of applied triangulation: Weighing different data sources. Journal of Mixed Methods Research, 12(2), 166-181. https://doi.org/10.1177/1558689816651032

Klock, A. C. T., Pimenta, M. S., \& Gasparini, I. (2018). A systematic mapping of the customization of game elements in gamified systems. Anais do Simpósio Brasileiro de Jogos e Entretenimento Digital. https://www.sbgames.org/sbgames2018/files/papers/ArtesDesignFull/188090.pdf

Kyewski, E., \& Krämer, N. C. (2018). To gamify or not to gamify? An experimental field study of the influence of badges on motivation, activity, and performance in an online learning course. Computers \& Education, 118, 25-37. https://doi.org/10.1016/i.compedu.2017.11.006

Lane, D. M., Scott, D., Hebl, M., Guerra, R., Osherson, D., \& Zimmer, H. (2014). Introduction to statistics. Online version.

Lavrakas, P. J. (Ed.). (2008). Encyclopedia of survey research methods. Sage Publications. https://doi.org/10.4135/9781412963947

Leaning, M. (2015). A study of the use of games and gamification to enhance student engagement, experience and achievement on a theory-based course of an undergraduate media degree. Journal of Media Practice, 16(2), 155-170. https://doi.org/10.1080/14682753.2015.1041807

Lee, J., Song, H.-D., \& Hong, A. J. (2019). Exploring factors, and indicators for measuring students' sustainable engagement in e-learning. Sustainability, 11(4), 985. https://doi.org/10.3390/su11040985

Lin, H.-M., Chen, W.-J., \& Nien, S.-F. (2014). The study of achievement and motivation by e-learning - A case study. International Journal of Information and Education Technology, 4(5), 421-425. https://doi.org/10.7763/ijiet.2014.v4.442

Mora, A., Riera, D., González, C., \& Arnedo-Moreno, J. (2017). Gamification: A systematic review of design frameworks. Journal of Computing in Higher Education, 29(3), 516-548. https://doi.org/10.1007/s12528-017$\underline{9150-4}$ 
Muntean, C. I. (2011). Raising engagement in e-learning through gamification. In Proceedings of the 6 th International Conference on Virtual Learning (ICVL) (pp. 323-329). Bucharest University Press. http://icvl.eu/2011/disc/icvl/documente/pdf/met/ICVL ModelsAndMethodologies paper42.pdf

Ning, B. (2018). A UX-driven design method for building gamification system. In A. Marcus \& W. Wang (Eds.), Design, User Experience, and Usability: Theory and Practice. DUXU 2018. Lecture Notes in Computer Science, vol 10918. Springer. https://doi.org/10.1007/978-3-319-91797-9_9

Ohn, M. H., Ohn, K. M., Yusof, S., D’Souza, U., Iswandono, Z., \& Mchucha, I. (2020). Development of novel gamified online electrocardiogram learning platform (GaMED ECG@ TM). In R. Alfred, Y. Lim, H. Haviluddin, \& K. O. Chin (Eds.), Computational science and technology (pp. 719-729). Springer. https://doi.org/10.1007/978-981-15-0058-9 69

Olsson, M., Mozelius, P., \& Collin, J. (2015). visualisation and gamification of e-learning and programming education. Electronic Journal of $e-L$ Learning, 13(6), 441-454. http://www.ejel.org/volume13/issue6/p452

Osipov, I. V., Nikulchev, E., Volinsky, A. A., \& Prasikova, A. Y. (2015). Study of gamification effectiveness in online e-learning systems. International Journal of Advanced Computer Science and Applications, 6(2), 71-77. https://doi.org/10.14569/IJACSA.2015.060211

Pauwels, L. (2012). A multimodal framework for analyzing websites as cultural expressions. Journal of ComputerMediated Communication, 17(3), 247-265. https://doi.org/10.1111/j.1083-6101.2012.01572.x

Pesek, M., Vučko, Ž., Šavli, P., Kavčič, A., \& Marolt, M. (2020). Troubadour: A Gamified E-learning Platform for Ear Training. IEEE Access. https://doi.org/10.1109/access.2020.2994389

Peterson, R., Marostica, M., \& Callahan, L. (1999). E-Learning: Helping investors climb the e-learning curve. https://pdfsecret.com/download/helping-investors-ride-the-elearningcurve 59f74966d64ab20a75173ebf pdf\#modals

Reich, J., \& Ruipérez-Valiente, J. A. (2019). The MOOC pivot. Science, 363(6423), 130-131. https://doi.org/10.1126/science.aav7958

Robson, K., Plangger, K., Kietzmann, J. H., McCarthy, I., \& Pitt, L. (2015). Is it all a game? Understanding the principles of gamification. Business Horizons, 58(4), 411-420. https://doi.org/10.1016/j.bushor.2015.03.006

Sailer, M., Hense, J. U., Mayr, S. K., \& Mandl, H. (2017). How gamification motivates: An experimental study of the effects of specific game design elements on psychological need satisfaction. Computers in Human Behavior, 69, 371-380. https://doi.org/10.1016/j.chb.2016.12.033

Seaborn, K., \& Fels, D. I. (2015). Gamification in theory and action: A survey. International Journal of HumanComputer Studies, 74, 14-31. https://doi.org/10.1016/j.ijhcs.2014.09.006

Seedorf, S., Thum, C., Schulze, T., \& Pfrogner, L. (2014). Social co-browsing in online shopping: The impact of real-time collaboration on user engagement. In Proceedings of the European Conference on Information Systems (ECIS) (pp. 1-15).

Staubitz, T., Willems, C., Hagedorn, C., \& Meinel, C. (2017). The gamification of a MOOC platform. 2017 IEEE Global Engineering Education Conference (EDUCON). https://doi.org/10.1109/educon.2017.7942952

University of California Berkeley. (2017). Evaluating resources: Home. http://guides.lib.berkeley.edu/evaluatingresources

Urh, M., Vukovic, G., \& Jereb, E. (2015). The model for introduction of gamification into e-learning in higher education. Procedia-Social and Behavioral Sciences, 197, 388-397. https://doi.org/10.1016/i.sbspro.2015.07.154

Zainuddin, Z., Shujahat, M., Haruna, H., \& Chu, S. K. W. (2020). The role of gamified e-quizzes on student learning and engagement: An interactive gamification solution for a formative assessment system. Computers \& Education, 145, 103729. https://doi.org/10.1016/j.compedu.2019.103729

Zichermann, G., \& Cunningham, C. (2011). Gamification by design: Implementing game mechanics in web and mobile apps (1st ed.). O’Reilly Media. 


\section{BIOGRAPHIES}

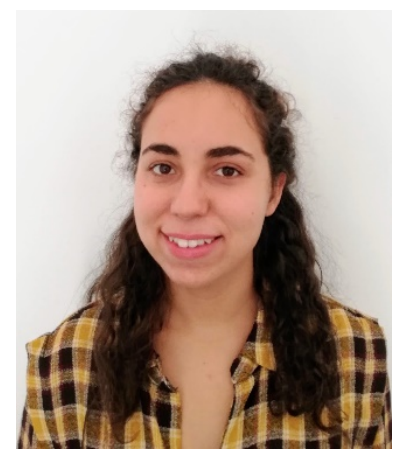

Sofia Rebelo attended to the Bachelor's in Economics between 2012 and 2015 and to the Master's in Management Information Systems between 2015 and 2017 at Lisbon School of Economics and Management (ISEG), having finalized both degrees. Sofia is a Quality Assurance Engineer at Novabase in Lisbon, Portugal, responsible for the manual and automated testing and also for the continuous testing implementation for over four years in several international projects in Telco business.

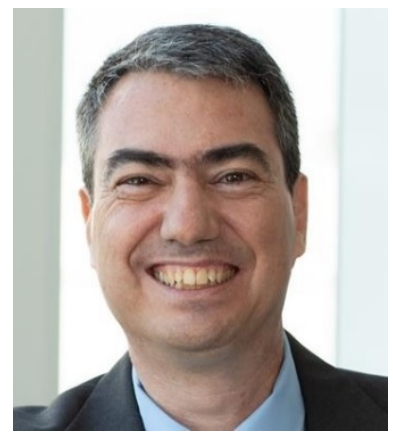

Pedro Isaías is an associate professor at the Information Systems \& Technology Management School of The University of New South Wales (UNSW - Sydney), Australia. Previously he was an associate professor at The University of Queensland, Brisbane, Australia. Before moving to Australia, he served at the Universidade Aberta (Portuguese Open University) in Lisbon, Portugal, where he was responsible for several courses and director of the master degree program in Management / MBA. Pedro was director of the master degree program in Electronic Commerce and Internet for 10 years. He was also an associate professor at Lisbon School of Economics and Management (ISEG) - University of Lisbon. 